\title{
Achievements with quality improvement in the NHS
}

\author{
Alison Kitson
}

National Institute for Nursing, Radcliffe Infirmary, Oxford OX2 6HE

Alison Kitson, director, Royal College of Nursing, Dynamic Quality Improvement Programme
This paper examines achievements in quality improvement in health care. It is not intended to be a comprehensive overview, rather to provide a brief description of how concepts of quality improvement have been used in nursing, to give examples of quality improvement in practice, and to highlight factors which need to be considered before achievements can occur.

On a bad day my definition of quality improvement reflects the sentiments of Denis Healey, who said that problems are never solved, merely altered. ${ }^{1}$ This, somewhat cynical, view perhaps reflects the experiences of many practitioners rather than the more well known rallying calls of the quality gurus. But on reflection, quality improvement rarely guarantees end points or solutions. It, too, emphasises the importance of movement towards a desired state, something which depends on common goals, and people working together, trusting one another, valuing contributions, and having the right information to make decisions.

Achievements with quality improvements therefore will manifest themselves as much in changes in behaviour, attitudes, and communications as in actual clinical practice. However, five years' experience working with the Royal College of Nursing's Dynamic Quality Improvement Programme has taught quality improvement is fragile and often elusive. It cannot be prescribed or conscripted into an organisation; its presence is more likened to work of the spirit than the application of the law.

\section{Why quality improvement}

It is this rather ephemeral aspect of quality which may explain why in health care we keep changing the terminology. Once everyone talked about professional standards of care those implicit value laden notions which carried with them both the moral requirements of the practitioner as well as his or her technical competence. The steady move towards focusing on technical competence is well documented, during this time the generic term standards of care gave way to more technology based terms such as accreditation, ${ }^{2}$ utilisation review, ${ }^{3}$ and audit. ${ }^{4}$

understand the key elements distinguishing quality improvement from other terms such as quality control, audit, or accreditation it is useful to look at developments within industry.

\section{Conceptual models of quality in industry}

Harvey described three distinct phases of development that have taken place in industry and which have direct parallels in health care (box). ${ }^{9}$ Quality at an individual level reflects the traditional craft based approach to work in which individuals were responsible for each step of the Deming cycle ${ }^{10}$ - namely, planning the work, doing it, checking on it, and taking action to correct any deficiencies. The model is familiar to those in professional practice and has been successful in promoting excellence. However, it is labour intensive and requires a long appprenticeship. It is also based on the notion of developing individual expertise and does not focus on teamwork.

The model of quality at an individual level gave way to the more technocratic approach namely, quality through inspection. From its origins in the scientific management movement led by Taylor ${ }^{11}$ at the beginning of the twentieth century, work began to be separated out: different external evaluators were responsible for quality and workers were responsible for one process only. Although this approach solved the problems of long apprenticeship and of meeting increasing demands for products, it soon led to reduced performance and low morale. Interestingly, while this approach was still being widely used the Horder committee in 1942 recommended its introduction to nursing practice. ${ }^{12}$ The separation of nursing into several discrete tasks is still much debated.

The most recent development has been the growth of the collaborative model of quality. Its underpinning principles include emphasis on the effective work of teams rather than individuals and reorientation towards synthesising the planning, doing, checking, and actioning of work. This philosophy has been embraced by total quality management (TQM) and continuous quality improvement (CQI) and its derivatives. Its hallmarks are in developing humane work systems and investing in people.

Although these terms all perported to be differed in their underlying assumptions, methodologies, and mechanisms for implementation. The most recent set of concepts and terms have embraced total quality management ${ }^{5}$ and quality improvement. ${ }^{6-8}$ To

\section{Dynamic quality improvement programme}

The principles of the collaborative model were the foundation stones of the Royal College of Nursing's Standards of Care Programme 


\begin{tabular}{|c|c|c|c|}
\hline \multicolumn{4}{|c|}{ Conceptual models of quality* } \\
\hline Quality & Individual & Inspection & Involvement and collaboration \\
\hline \multirow[t]{3}{*}{ Focus } & Individual responsibility & Identifying defects & Improving processes \\
\hline & Integral part of work & Work separated out & $\begin{array}{l}\text { Quality seen as a search for } \\
\text { continuous improvement }\end{array}$ \\
\hline & $\begin{array}{l}\text { End product of highly skilled } \\
\text { work }\end{array}$ & $\begin{array}{l}\text { Workers at fault for poor } \\
\text { quality }\end{array}$ & towards a goal of excellence \\
\hline \multirow[t]{3}{*}{ Means of achieving quality } & Selection & $\begin{array}{l}\text { Systems techniques of } \\
\text { inspection }\end{array}$ & Developing systems \\
\hline & Training & $\begin{array}{l}\text { Workers viewed as lazy, } \\
\text { responding to financial } \\
\text { reward }\end{array}$ & Investing in people \\
\hline & $\begin{array}{l}\text { Individuals highly trained, } \\
\text { respected for skills and } \\
\text { commitment }\end{array}$ & & $\begin{array}{l}\text { Workers viewed as valuable } \\
\text { assets to whole process }\end{array}$ \\
\hline \multirow[t]{5}{*}{ Key characteristics } & Craft based & Scientific work management & $\begin{array}{l}\text { Work achieved through } \\
\text { teams }\end{array}$ \\
\hline & Labour intensive & Task activity analysis & Empowering workers \\
\hline & Long apprenticeship & $\begin{array}{l}\text { Poor performance, low } \\
\text { morale }\end{array}$ & Involving whole team \\
\hline & $\begin{array}{l}\text { Employee control over } \\
\text { planning, doing, checking, } \\
\text { and acting }\end{array}$ & $\begin{array}{l}\text { Employees responsible ;for } \\
\text { doing only; rest of cycle } \\
\text { controlled by managers and } \\
\text { specialists }\end{array}$ & $\begin{array}{l}\text { Employees responsible for } \\
\text { planning, doing, checking, } \\
\text { and acting }\end{array}$ \\
\hline & & & $\begin{array}{l}\text { Key role of managers, } \\
\text { leaders is a supporting, } \\
\text { enabling role }\end{array}$ \\
\hline
\end{tabular}

(now the Dynamic Quality Improvement Programme). In 1987 the college stated how it was going to encourage the introduction and use of quality concepts to improve nursing practice. In setting out the conceptual framework for its quality assurance programme, ${ }^{12 a}$ the college made a firm commitment to involve practitioners directly in setting and auditing their own standards and in encouraging local ownership and control of these activities. It also endorsed an organisational system which devolved power to local level, was driven by local standard setting or quality improvement groups, and supported by trained facilitators. In the late 1980 s this was a radical departure from the more inspection based nursing quality assurance systems being used (preformulated tools such as Monitor, ${ }^{13}$ Qualpacs, ${ }^{14}$ and the Phaneuf audit. ${ }^{15}$ A major educational programme had to be set up to help nursing departments take on this new philosophy and methodology. ${ }^{8}$

By the late 1980 s the college's quality improvement approach was reported to be used in over half the district health authorities in the United Kingdom. ${ }^{15}$ The Audit Commission recommended its use as one method of auditing nursing standards, ${ }^{16}{ }^{17}$ and recently a three and a half year evaluation study of the effect of local standard setting and audit on nursing actions and patient outcomes reported significant improvements. ${ }^{18} 19$ Despite this evidence several issues exist which if not recognised and dealt with, will undermine any potential benefits brought about by involvement in quality improvement activity.
How quality improvement systems work Two key factors seem to be essential to success in improving quality: getting appropriate groups of clinical staff together to set, audit, and evaluate their care and having that process supported by a trained facilitator. The steps around the quality improvement/audit cycle are now well accepted (figure), but the college's programme emphasises the need for the team of practitioners to be involved in each of those steps personally and to manage the behavioural and attitudinal changes that need to occur before practice changes.

Because staff have been involved in setting and auditing their own standards the commitment to take action after data analysis tends to be greater. In fact, both experience and reserch indicate that improvement in practice often happens when a team begins to look more thoroughly at a particular area of care. ${ }^{18-21}$ Auditing acts as a validator of that activity and can outline other areas for further work. The closing of the audit loop ${ }^{22}$ is therefore more likely to occur when groups have been involved in each step.

The importance of successfully moving around each step of the audit cycle has been identified by several authors. ${ }^{23-25}$ What has not been systematically evaluated is the effect of separating out the defining, monitoring, and action stages of the cycle and the issues of ownership over the defining and auditing of standards. These aspects of quality improvement - that is, ownership of the change and personal responsibility for effecting behavioural and attitudinal change have been identified by several investigators. ${ }^{5-7} 92627$ 
1 Identify area of work/process

2 Convene a group

3 Check current knowledge of process

4 Understand reason for variation

5 Identify what you wish to improve

1 Interpret results

2 Negotiate view

3 Devise action plan

4 Act

5 Re-evaluate

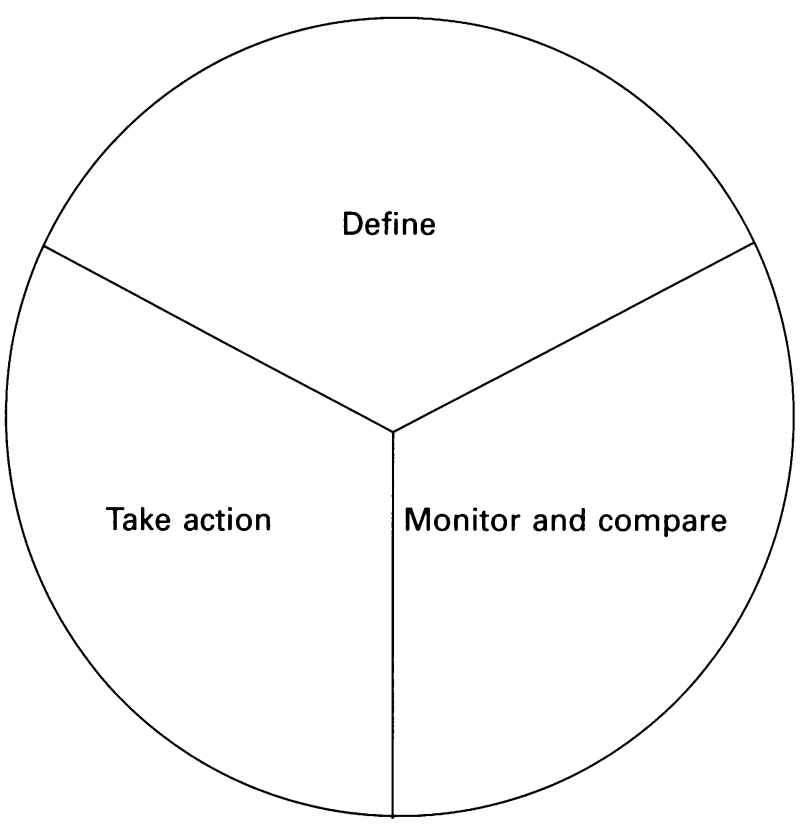

1 Plan how to implement new activity

2 Develop audit tool

3 Implement activity

4 Collect data

5 Compare with previous practice
A further issue for debate is the relation between systematically derived national guidelines and possibly less rigorous local guidelines or standards. ${ }^{28}$ Again, an assumption is made that the most important factor is to have the most up to date research evidence to feed into the quality improvement cycle. However, evidence suggests that staff can develop their own guidelines locally, and despite deviation from the "ideals" of a national guideline patient outcomes and staff performances can still be seen to have improved. ${ }^{18} 19$ This seems to suggest that factors other than the acquisition of the most recent scientific knowledge affect staff behaviour and patient outcomes. Clearly, certain key aspects of knowedge must be identified before local groups can be effective. However, outside these core items acceptable variation must exist. Distinguishing between core elements and contextual aspects of care is another area where little guidance is currently available.

\section{Successes with quality improvement}

The apparent tension between the role of scientific knowledge in informing processes to improve performance and the dynamics of interpersonal relationships, attitudes, and teamwork has been recognised previously. Berwick identified the need to acknowledge the interdependencies that exist between health care workers before any real progress can take place in improving patient care. ${ }^{726}$ Auditing practice cannot be viewed as a policing exercise and all the players must be involved in assessing what counts as a quality service. To evaluate health care processes - as expounded within the quality of improvement approach - means that both scientific knowledge and interpersonal, value based information must be integrated. What is interesting is that quality improvement initiatives led by nurses have tended to focus on the interpersonal, organisational aspects of care whereas those led medically tend to focus on more discrete technical interventions.

This dichotomy, although understandable in terms of the training and professionalisation processes that occur within disciplines has potentially negative effects on the philosophy and practice of attempted integrated quality improvement. Although there is evidence that several nursing led initiatives have improved practice (box), their apparent failure to produce numerical data as evidence to support the improvement means that their professional colleagues view the improvements as either insignificant or unsubstantiated, thus reinforcing the divisions between groups. This situation raises two very important issues: Why do nursing quality improvement activities tend not to focus on the collection of numerical data as a primary objective? How can interdisciplinary quality improvement initiatives be encouraged which overcome the variety of approaches to data collection.

\section{Nurses and numbers}

There are at least two possible reasons why nurses tend not to collect numerical data. Firstly, audit assistants have not supported nursing audit and therefore record review and auditing large numbers has been difficult. Secondly, nurses tend to select topics for quality improvement which are related to continuity of care or providing support or information, which are difficult to quantify 


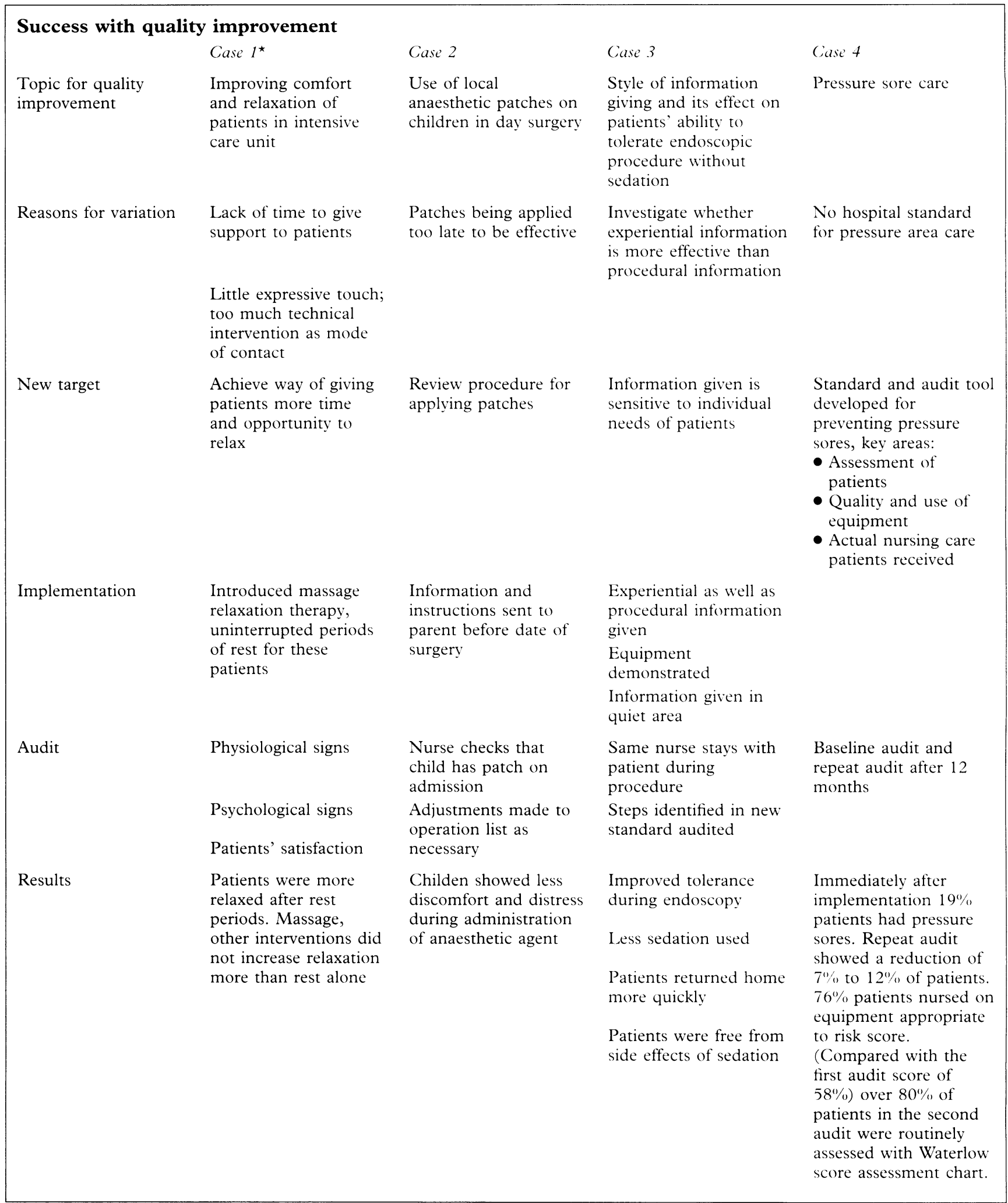

After Dunn. ${ }^{29}$

and not usually documented precisely. The task of producing a clear audit tool with precise numerical data is possible but is often outside the skill and experience of the group unless supported by an experienced facilitator. Nurses generally do not gather routine data on their patients (except for accident rates, pressure sores). This habit needs to be developed as routine indicators such as postoperative pain, comfort levels, and satisfaction with information could be used as broad measures of quality of care. Additionally, local support is needed to help practitioners to see "the big picture" - that is, how their particular intervention with patients belongs to a collection of similar interventions which can be evaluated.

It is important to recognise the traditional orientation of health care groups, particularly in the move towards clinical audit and more interdisciplinary work. The experience of many nurses involved in audit projects is that colleagues tend not to be interested or committed to the topics identified as areas for 
investigation. This may reflect quite profound differences in methodological perspectives and ways of interpreting patient care. However, within the framework of quality improvement it is these very differences which need to be synthesised in order to achieve a complete picture of the process of care delivered to patients. Therefore the creative tension existing between members of the health care team when they come together to discuss topics for quality improvement must be harnessed. Managing the dialogue, sorting out the group dynamics, helping individuals become team players are complex tasks. In reality quality groups are usually left to muddle through as best as they can. This whole area of facilitating effective group work is an important dimension in successful quality improvement initiatives.

\section{Evidence for quality improvement}

A general rule should be that one source of evidence alone should not be seen as sufficient to indicate improvement. Thus we should be as sceptical of a set of statistics showing improvements without descriptions of actual change as we should be aware of descriptions without numerical data. The ODySSSy project illustrates this point.$^{18}{ }^{19}$ In this quasiexperimental design the nursing management of postoperative pain in five wards setting standards was compared with that in five matched control wards. Three of the experimental wards over the study period (12 months) showed an improvement in patients' pain scores whereas two experimental wards and none of the control wards showed similar improvements. These data were collected by members of the research team and were independent of the local audits undertaken by staff themselves. While the local audits showed that more patients were using pain assessment charts in the three wards in which improvements were recorded by the research data they also recorded an improvement in one of the two experimental wards not showing an improvement according to the research data. Such findings raise fundamental questions about the reliability of local audits, their timing, and the sustained effects of improvements alleged to have been achieved in practice. ${ }^{30}$

More interestingly, when the process data (on group activity and dynamics) from the five experimental wards were compared with the results on patient outcomes very strong patterns of staff motivation and related patient pain scores were detected. In other words, when staff were highly motivated and keen about their task within the group more patients reported low pain ratings on graphic rating scales administered on the third postoperative day. Conversely, when staff were demotivated patients' pain scores increased. ${ }^{17}$ This would seem to indicate that certain process measures of how the group is working may be quite sensitive indicators of patient experiences. Using process data to inform outcome results is seen as important for further exploration.

\section{Data collection and review techniques}

The message of quality improvement is that it combines good teamwork and motivation with well developed skills in statistical analysis and detecting variations in practice over and above normal limits. The importance of laying down good data systems, informed by scientifically based practice guidelines or standards, is a pressing need for all groups. By involving local practitioners in this activity the conventional wisdom can be compared with the scientific evidence. Where the two are in discord then by the fact that a dialogue has been established through quality improvement, there is a greater rather than a lesser chance of practitioners taking on new ways of doing things.

\section{Precursors to success}

Quality improvement is both a philosophy and a methodology. It is important to locate oneself, one's colleagues, and one's organisation in the conceptual framework defining approaches to quality. In what way is quality improvement viewed in an organisation? Does one group resist it because it is perceived as an inspection model? How can the vision for quality as collaboration and involvement be spread? Can we cope with the consequences of this message in terms of breaking down hieararchies, encouraging greater teamwork, and of group problem solving?

The organisational structure set up to support quality improvement must be clear and not hierarchical: leaders for quality have to be identified and supported; interdependencies acknowledged; and common goals emphasised, reducing the areas for division and discord. The mechanics of quality improvement - selecting topics, analysing processes, and setting and auditing new standards - must be communicated to everyone within the organisation using the same terminology and the same basic techniques. All of this new activity must be supported by trained agents of change or facilitators who know how to get the best out of groups. And finally the best incentive for improvement is to ensure regular feedback of those successes - how things improve for the patient, for the staff, and for the organisation. When quality improvement is progressing well there should be no losers.

I thank Chrissie Dunn and Geraldine Cunningham, together with their colleagues in West Berkshire and the Brompton Hospital, for providing me with the examples of improvement in patient care used in this paper.

1 Healey D. The time of my life. London: Penguin, 1989.

2 King's Fund Centre Quality Improvement Programme. Organisational audit (Accreditation UK) Standards for an acute hospital. London: King's Fund Centre, 1990.

3 Payne BC. Hospital utilisation review manual. Ann Arbor: University of Michigan, 1966.

4 Irvine D, Donaldson L. Quality and standards in health care. In: Beck JS, Bouchier IAD, Russell IT, eds. Quality care. In: Beck JS, Bouchier IAD, Russell IT, eds. Quality assurance in medical care.

5 Berwick DM, Enthoven A Bunker JP Quality management in the NHS: the doctor's role. BMF management in

6 Peters D. Measuring quality: inspection or opportunity? Holistic Nursing Practice 1991;5:1-7.

7 Berwick D. Heal thyself or heal thy system: can doctors help to improve medical care? Quality in Health Care 1992;1(suppl):52-8. 
8 Royal College of Nursing Dynamic Quality Improvement Programme. Facilitator's workshop manual. Oxford: National Institute for Nursing, 1994

9 Harvey G. Nursing quality: an evaluation of key factors in the implementation process [PhD thesis]. London: South Bank
ind University, 1993

10 Deming WE. Out of crisis. Cambridge: Cambridge University Press, 1991

11 Taylor FW. Scientific management. New York: Harper, 1911.

12 Horder. Royal College of Nursing, Nursing Reconstruction Committe Report. I ondon: Roval College of Nursing. 1942.

12a Kitson AL. Framework for quality: London: Royal College of Nursing, 1989.

13 Goldstone LA, Ball JA, Collier MM. Monitor: an index of the quality of nursing care for acute, medical, and surgical the quality of mursing care for acute, medical, and surglcal
wards. Newcastle upon Tyne: Newcastle upon Tyne wards. Newcastle upon Tyne:
Polytechnic Products, 1983 .

14 Wandelt MA, Ager JW. Quality patient care scale. New York: Appleton-Century-Crofts, 1974

15 Phaneuf MC. The mursing audit: self regulation in nursing practice. New York: Appleton-Century-Crofts, 1976.

15a Kitson AL, Harver G. Nursing quality assurance directom: Roval College of Nursing, Standards of Care Project. London: RCN, 1989.

16 Audit Commission. the aitue of patients: better us of zeard nursing resources. London: HMSO, 1991

17 Audit Commission. Making time for patients: a handbook for ward sisters. London: HMSO, 1992

18 Royal College of Nursing Dynamic Quality Improvement Programme. The impact of a nursing quality assuranci Programme. The impact of a nursing qualty assuranci
approach, the Dynamic Standard Setting System (DySSSW) approach, the Dynamic Standard Setting System (DVSSSV) Vol 1. Oxford: National Institute for Nursing, 1994. (Executive summary report No 4.)
19 Roval College of Nursing Dynamic Quality Improvement Programme. The impact of a mersing quality assurance approach the Drnamic Standard Setting Sistem (I) YSSSy) on mersing practice and patient outcomes. Vol 2. Oxford: National Institute for Nursing, 1994. (Study report No 4.)

20) North of England Study of Standards and Performance in General Practice. Medical audit in general practice. I. Effects on doctors clinical behaviour for common childhood conditions. BMF 1992;304:1480 4 .

21 North of England Study of Standards and Performance in General Practice. Medical audit in general practice. II. Effects on health of patients with common childhood conditions. BMf 1992;304:1484-8.

22 Crombie IK, Davies HT. Missing link in the audit cycle. Quality in Health Care 1993;2:47 8

23 Russell IT, Wilson B. Audit: the third clinical science. Quality in Health Care 1992;1:52 5.

24 Gabbav J, Lavton AL. Evaluation of medical records in a district general hospital. Quality in Health Care 1992; $1: 43-7$.

25 Firth-Cozens J, Storer D. Registrars' and senior registrars perception of their audit activities. (Mality in Health Car 1992;1:161-4

26 Berwick D. Continuous improvement as an ideal in health care. N I:ngl 7. Med 1989;320:54-6.

27 Harrey G. An evaluation of approaches to assessing the quality of nursing care using (predetermined) yuality assurance tools. F Adr Nuring 1991;16:277-86.

28 Grimshaw JM, Russell IT. Effects of clinical guidelines on medical practice: a systematic review of rigorous medical practice: a systematic revien

29) Dunn C. Improving intensive care. Nursing Times 199()$; 86: 32-4$.

30) Kitson AL, Harvey G, Hyndman S, Yerrell P. A comparison of expert- and practitioner-derived criteria for post-operative pain management. 7 Adr Nirring 1993;18:218-32 